\title{
Editorial
}

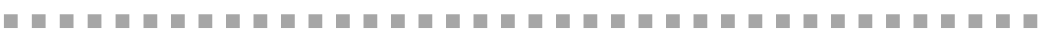

\section{La vocación del investigador}

El filósofo español Eduardo Nicol, uno de los brillantes intelectuales que el franquismo trajo a México, nos enseña que el hombre es un ser ontológicamente libre e inacabado que va produciendo su propio ser a lo largo de su vida, a diferencia de todos los demás seres que nacen siendo ya lo que son. El hombre, dice Nicol, no posee un ser predeterminado por lo que recibe como herencia biológica sino que tiene que construir su ser incompleto con su propio obrar. Esto implica, según nuestro entender, que la vocación puede jugar un papel definitorio crucial en la conformación del ser de todo hombre, toda vez que puede ser la motivación que impulse y oriente su auto complementación-maduración por el resto de su vida. Pero, ¿qué es la vocación? Sin pretender definirla a cabalidad, recurramos de nuevo a Nicol para enriquecer nuestra concepción de ella. Según este ilustre pensador, la vocación, del latín vocatio, es un llamado que el hombre recibe de sí mismo pero a través del ejemplo que le dan otros hombres que han cumplido una vocación, a quienes él elige libremente imitar para completar su propio ser.

Es evidente que el poseer vocación para realizar aquello a lo que uno se dedica es deseable por diversas razones; la primera que viene a nuestra mente es que el poseerla se traducirá en un disfrute de la labor en lugar de un carga penosa. Esto por sí solo sería motivo suficiente para desear que la vocación inspirara el trabajo, lo mismo del campesino y el albañil que el de la secretaria, el policía, el abogado y el psicólogo, por citar algunas ocupaciones. Sin embargo, lamentablemente, las múltiples necesidades humanas, la desigualdad social y otros factores impiden que todos se dediquen a aquello que realmente los motivaría. Pero para fortuna del hombre, su propia naturaleza polifacética, multihábil, le ofrece la posibilidad de adaptarse al ejercicio de muy variados menesteres, incluso de aquellos que no haya escogido altamente motivado sino orillado por las circunstancias, y a desempeñarlos suficientemente bien, sin que ello le acarree necesariamente frustración. No obstante, existen ciertos quehaceres que exigen como requisito sine qua non para su buen desempeño el sentirse atraído hacia ellos de manera muy especial, es decir, por una genuina vocación. Entre las ocupaciones en las que la presencia de ésta es indispensable se encuentran el ejercicio de las bellas artes, la docencia y la 
investigación científica. Particularmente en las dos últimas la vocación tiene repercusiones muy relevantes sobre la calidad del desempeño y de sus frutos, a tal grado que éstos pueden arruinarse si aquélla no existe. Únicamente un docente con auténtica vocación por el conocimiento posee el sentido de responsabilidad académica que demanda su trascendente labor, el cual le impide, por ejemplo, dictar cursos o pretender investigar en áreas que no conoce suficientemente bien, así como improvisar respuestas falsas para evitar tener que reconocer frente a sus discípulos que no lo sabe todo. Pero centrémonos en la labor investigativa de los académicos para examinar con un poco de más detalle por qué es que aseveramos que en tratándose de ella el que se disponga de vocación no es un rasgo meramente deseable en el investigador o un adorno prescindible de su tarea, sino un elemento vital que puede impactar negativa o positivamente los frutos buscados.

La vocación del investigador es como el fármaco con el que todo médico desearía contar: con alto poder terapéutico preventivo, de muy amplio espectro y sin riesgo de causar reacciones secundarias. Es un antídoto contra una extensa serie de padecimientos a los que suelen estar predispuestos algunos que se ostentan como investigadores; es a la vez un poderoso estimulante del trabajo arduo y persistente, tan necesario en la persecución de nuevos saberes. Funciona como eficaz vacuna contra la novelería, mal que enferma a quienes interesados más por los resultados de investigación que parezcan novedosos e impactantes que por los que sean verdaderos aunque discretos, están siempre dispuestos a cambiar de una línea de investigación a otra sin estar al tanto del estado del arte correspondiente, con tal de abordar temas de moda, muy socorridos, por cierto, en nuestras disciplinas, o problemas cuyo estudio pueda acarrearles prestigio u otros beneficios. Inhibe el desarrollo del síndrome de vanidad, que impide a quien lo padece reconocer que se ha equivocado al afirmar algo en algún diálogo académico, oral o escrito, aunque esté plenamente consciente de ello. La vocación previene igualmente de contraer el mal de defraudación, merced al cual algunos investigadores son capaces de alterar los resultados de sus indagaciones en pos de obtener fondos para apoyar su labor, así como brillo personal. Aunque los casos de fraude científico han existido desde tiempo atrás, la enfermedad ha proliferado recientemente a tal grado que en los Estados Unidos hubo de crearse en 1989 la "Oficina para la Integridad Científica”, transformada en 1993 en "Oficina para la Integridad de la Investigación”, con objeto de luchar contra el engaño científico. La auténtica vocación por el conocimiento es, en suma, el único inmunizador capaz de impedir que el investigador jamás anteponga sus intereses personales al predominio de la verdad. 
Parte de los benéficos efectos producidos por la vocación por el saber se deben a que estimula la segregación de humildad y honestidad académicas, que fluyen en la sangre de los verdaderos investigadores. Ella, por ejemplo, motivó a Darwin a reconocer motu proprio, por escrito y ampliamente, que Patrick Mathew se había anticipado a su concepción del principio de la selección natural de las especies. Es este mismo fluido sanguíneo el que inspiró a Sócrates a declararse un ignorante frente a la inmensidad de los misterios del cosmos, y a Newton a expresar la famosa frase "Si he visto más allá, es por haberme colocado en los hombros de gigantes”. La misma modestia denotaban los sabios mexicas o tlamatini -aquellos que fueron capaces de crear un calendario astronómico más preciso que el que se usaba en aquella época en Europa—, quienes, según relata León Portilla, no creían que pudiera lograrse un conocimiento claro y preciso, libre de toda objeción, como dejaban ver en la línea de un poema que reza: "puede que nadie llegue a decir verdad en la tierra”.

Como estimulante del trabajo empeñoso y perseverante, en el caso de los genuinos investigadores, célebres o incógnitos, la vocación usualmente toma la forma de auténtica pasión por la búsqueda del conocimiento sin más afán que el conocimiento mismo. La historia de la ciencia nos enseña que dicha pasión ha jugado un rol singular en el desarrollo del conocimiento, toda vez que aun en el caso de los más eminentes genios del quehacer científico su inteligencia extraordinaria generalmente ha tenido que estar acompañada de un esfuerzo intenso, denodado, para poder dar a luz nuevos saberes sin desfallecer ante los innumerables obstáculos y frustraciones que pavimentan el camino del descubrimiento. Darwin, por ejemplo, con todo y su brillante intelecto, tuvo que dedicar más de veinte años de intensa labor para concebir El origen de las especies, su obra máxima. Por ello no es casual que dedique un apartado especial de su autobiografía, titulado "Perseverancia en el estudio", para destacar el relevante papel que ésta y su amor por la ciencia, que calificó de "constante, firme y ardoroso", jugaron en el logro de su teoría. Marx hubo de dedicar cerca de veinte años también para escribir El capital, que nunca concluyó, sufriendo miseria y enfermedad en aras de poder dedicarse a la investigación que lo apasionaba. Al prevenir a los lectores "que buscan la verdad" acerca de las dificultades de los primeros capítulos de dicha obra, escribió: "En la ciencia no hay calzadas reales, y quien aspire a remontar sus luminosas cumbres, tiene que estar dispuesto a escalar la montaña por senderos escabrosos." Por su parte, Elton Mayo, Roethlisberger y todo un equipo de colaboradores dedicaron en conjunto más de 12 años, en plena gran depresión, a sus famosas inves- 
tigaciones en la planta Hawthorne, las cuales incluyeron, además de los consabidos experimentos, la realización de más de 21,000 entrevistas en profundidad, de hora y media de duración cada una. Ello fue posible, sin duda, gracias a un real interés por el conocimiento.

La actitud interrogadora del hombre ante el universo, su inquietud persistente de preguntarse y responder, su anhelo de saber, coadyuvaron substancialmente a su conformación como homo sapiens; hoy en día, el amor por la verdad que palpita de manera intermitente en el espíritu del buscador de razones, la vocación del investigador, no sólo es necesaria para conseguir nuevas verdades, es imprescindible para seguir haciéndonos humanos día con día, de aquí que nunca sea suficiente insistir sobre su trascendencia.

Jorge Ríos Szalay 